\title{
An Approach of Software Requirements Elicitation Based on the Model and Notation Business Process (BPMN)
}

\author{
Marcos A. Chiarello, Maria Cláudia F. P. Emer, and Adolfo Gustavo S. S. Neto
}

\begin{abstract}
The high competitiveness between business organizations demands a constant innovation and evolution in their productive processes, requiring information systems to be produced and modified with the same swiftness. However, the software requirements elicitation, considered a critical step to the success of the software development, many times it is still done without an effective warranty of its alignment with the problems and needs inherent to the business.

This work proposes the development of an approach for software requirements elicitation through the Model and Notation Business Process (BPMN). From the approach point of view of this problem, will be used a qualitative research, because focuses on conceptual issues, patterns, opinions expressed and their respectives analyzes and, from the point of view of technical procedures, it is based on case studies. The preliminary results of the studies indicate that its use is viable and can assist the result effectiveness of the software requirements elicitation.
\end{abstract}

Index Terms-Business process modeling, requirements definition, software development, software engineering.

\section{INTRODUCTION}

The uncertainty and the constant changes in the economic environments persist, globalization, strategic and technological pressures make evident that the great facilitator can be informatics. According to [1], the information passes to be a strategic resource for the organizations and the Information Technology (IT) must be able to adapt to these changes. In this context, understanding and mapping the corporation processes is a way to create good information systems. [2] corroborates the claim that neither an understanding of the stakeholders needs, nor of the system characteristics are, by themselves, adequate for communicating the programmer exactly what the software should do.

The elicitation of requirements, within the development process, is not a trivial activity. It follows perhaps by abstract characteristics of the software [3]. This activity is considered critical to the development process of the software project. However, many times elicitation process faces difficulties due to low or the lack of experience of the analysts to meet the requirements of users [4].

According to [5], the requirements elicitation based on

Manuscript received July 10, 2013; revised September 9, 2013. This work was supported in part by the Federal Technological University of Paraná, Brasil. An approach of software requirements elicitation based on Business Process Model and Notation (BPMN). -

The authors are with the Federal Technological University of Paraná, Brasil (e-mail: chiarello@celepar.pr.gov.br,mclaudia@dainf.ct.utfpr.edu.br, adolfo@dainf.ct.utfpr.edu.br). business processes brings benefits to standardize a language for all phases of the project, improving the interface among the various activities, as well as the accuracy and adequacy of the software for the organization real needs.

In literature, it can be observed that the employment of the modeling of business processes, through the notation BPMN, can assist in the elicitation of requirements, because with the model of business processes it is possible to map not only the work flow, but a series of information related to the activities and identify existing informational systems or even requirements for the construction of new systems [6]-[8].

The proposed work presents a contribution to the theme Requirements Engineering. As expected benefits it is possible to highlight: guiding analysts of requirements in the task of elicitation of requirements for software based on notation BPMN; Improve the identification and definition of the requirements; A greater integration between the stakeholders and developers of systems of information. To demonstrate the application of the proposed approach, two (2) case studies have been conducted.

This article is organized into 6 Sections: Section II presents the concepts that justify this Article; Section III describes the proposed approach; Section IV describes the preliminary results; related case studies are commented in Section V; and the conclusions can be found in Section VI.

\section{CONCEPTS}

The following concepts served as base for this research.

\section{A. Model and Notation Business Process BPMN}

BPMN is a graphical notation, maintained by the Object Management Group - (OMG), created for the representation of business processes and based on workflows [9], providing easy reading and understanding by all stakeholders in the business.

The four basic categories of elements in BPMN notation are: the work flow objects (Events, Tasks, and Decisions); connection objects (streams and Sequence Messages and Associations); swim lanes (pools and lanes) and artifacts (Data objects, Annotations and Groups) [9], [10].

An example of its use is presented in Fig. 1, in which is possible to observe a partial modeling of an inventory process. In this figure it is possible to identify the four basic elements of the notation: swim lane representing the flow Registry; Work flow objects representing the tasks Documents Reception, Judicial approval, Drafting, Documents guiding and Guiding PGE; also as flow objects decisions are represented by lozenges with a circle in the center and the connection objects, by not dotted arrows representing the other sequence flow process. 


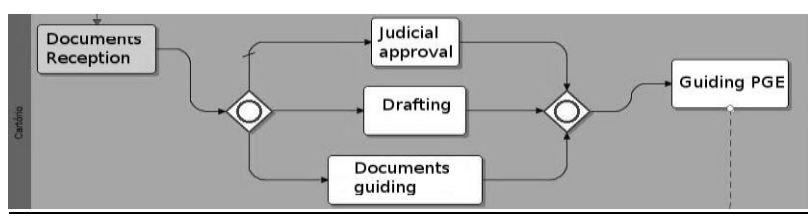

Fig. 1. Inventory process.

\section{B. Requirements}

The requirements of a system are the services descriptions provided by the system and operational restrictions [11]. Despite of apparently being simple, for many people it still generates doubt. [11] describes these doubts when he says that for some people is enough a declaration on the high level of abstraction, but for other it is necessary a formal and detailed description.

For [3], a requirement is an ability that is imposed on a system and, as such, the challenge is to understand users' problems in their culture and language and build systems that attend their needs. For the [12], the requirement is a condition or capacity needed for a user to solve a problem or achieve an objective.

The requirements can be classified as functional or non-functional. The functional requirements are directly related to the functionality of the software [4].

The non-functional requirements express the conditions or specific features under which the software must work. These requirements pose restrictions on the system [4].

\section{PROPOSED APPROACH}

Unlike the traditional techniques for the elicitation of requirement, in the proposed approach (Fig. 2), which has been described using the notation BPMN, there is a specific sub-process for the modeling of the business process, with which information systems can be constructed in order to support their administrator .

The proposed approach includes:

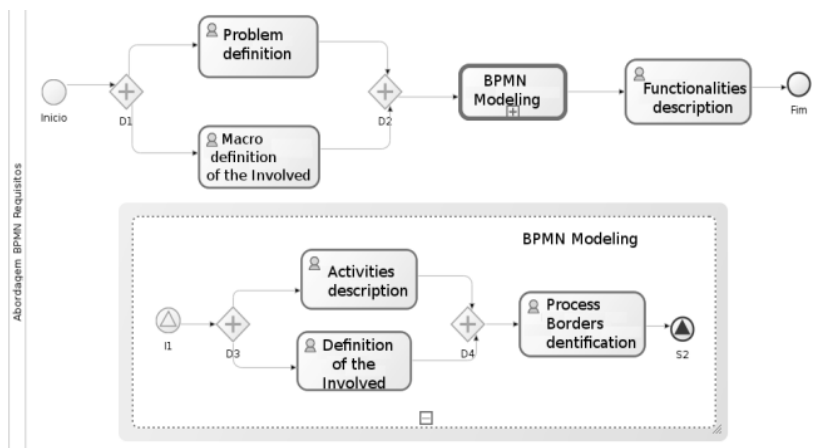

Fig. 2. Requirements elicitation approach.

1) Problem definition: Activity geared to understanding the problem, at a high level (brad context without detail). Delimitation of the scope aiming at an agreement with the involved.

2) Macro definition of the Involved - it is important in this activity to define, in addition of the main Stakeholders, the owner of the process. This person has the responsibility to ensure the alignment of the organization strategies, as well as answering eventual doubts.

3) BPMN Modeling - The process modeling (represented in
Fig. 2 as a sub-process) is complex and demands effort and dedication of those involved, because it is the graphical representation of reality. This modeling is started with macro processes for the definition of organizational strategies. After refined, the corporative procedures are identified and, soon after, it is possible to perform the mapping of activities, in which the rolls and responsibilities for the correct execution for each activity are assigned.

4) Description of activities - Consists in describing the activities, manual or automated, performed in the process, considering issues such as: reason, subjects, measuring tools, objects, rules, results and work division.

5) Definition of the Involved - Consists in identifying all the involved in the process. This identification involves all the individuals who somehow affect or even are affected by the results achieved.

6) Process Borders identification - Activity geared to identify the existence of other systems, legacy or not, or even other processes that need or don't need to be mapped.

7) Description of features - Consists in identifying the features, the functional and not functional requirements (what the system should do as well as what is expected) to meet the needs of the business modeled.

Therefore, the application of the proposed approach for the requirements elicitation based on notation BPMN, in the initial phase of the development processes, aiming to facilitate the construction and continuous improvement of the informational systems, operational visibility, documentation of the tacit knowledge of the involved areas, improvement of the quality of the services provided and consequently the reduction of the risks and the customers satisfaction, shows itself viable.

\section{PReliminary Results}

Initially, a guide for the processes modeling using the notation BPMN was prepared [13], for this research project, with the objective of providing a better comprehension of the notation to the requirement engineers. The guide presents the kinds of connectors used in the notation BPMN and examples their use. The guide's creation was based on the works of authors [10] and [14], as well as, in knowledge acquired in two Hands-On promoted by [15] and [16].

Practical studies in processes modeling tools (installation and tests) were performed with the aim of selecting a tool for the implementation of the research project. Some tools were discarded because the solutions did not meet the specified requirements for the selection as: Opened standards, free software, Active community, Support the standard of the notation BPMN, Graphical tool to visualize, create and edit business processes, editor WYSIWYG and Validation of dynamic consistency. As a result of this evaluation, the solution of Bonita Studio was selected for meeting the defined criteria [17].

With the approach to elicitation of requirements employing BPMN, the guide to modeling of business processes developed and the modeling tool selected, another 
stage of the research was started. This step was divided in three stages: application, use and validation of the proposed approach. Below, these steps are described and the preliminary results are pointed out.

\section{A. Stage I}

Approach application, with the objective of investigating the traditional techniques of the requirements elicitation for its use with the proposed approach as well as identify possible improvements to the proposed model.

This step was performed with a set of thirteen (13) projects such as: Line of Virtual Tourism, Mobile Project of Electronic Record among others.

TABLE I: ReQuiREMENTS/PhASE OF THE PROJECT - CASE STUDY I

\begin{tabular}{|c|c|c|c|c|c|c|c|c|c|}
\hline Projects & Team & Technique Applied & Hiring & Analysis & Design & Build & Transition & Requirements after Approach & Total Requirements \\
\hline Case I & 3 & Interviews / Workshops & 50 & 28 & 2 & 2 & 0 & 4 & 86 \\
\hline Case II & 2 & Interviews / Scenarios & 45 & 20 & 0 & 1 & 0 & 8 & 74 \\
\hline Case III & 2 & Interviews / Scenarios & 77 & 10 & 0 & 0 & 0 & 11 & 98 \\
\hline Case IV & 2 & Interviews / Brainstorming & 27 & 23 & 0 & 3 & 0 & 6 & 59 \\
\hline Case V & 3 & Interviews / Brainstorming & 61 & 29 & 0 & 0 & 0 & 8 & 98 \\
\hline Case VI & 1 & Interviews / Scenarios & 69 & 12 & 0 & 0 & 0 & 10 & 91 \\
\hline Case VII & 1 & Interviews / Workshops & 32 & 13 & 0 & 0 & 0 & 2 & 47 \\
\hline Case VIII & 1 & Interviews / Brainstorming & 75 & 13 & 3 & 0 & 0 & 9 & 100 \\
\hline Case IX & 1 & Interviews / Workshops & 43 & 5 & 4 & 0 & 0 & 2 & 54 \\
\hline Case $\mathrm{X}$ & 3 & Interviews / Scenarios & 84 & 22 & 1 & 0 & 0 & 9 & 116 \\
\hline Case XI & 2 & Interviews / Brainstorming & 87 & 10 & 0 & 0 & 0 & 11 & 108 \\
\hline Case XII & 2 & Interviews / Workshops & 103 & 25 & 2 & 2 & 0 & 5 & 137 \\
\hline Case XIII & 3 & Interviews / Workshops & 59 & 30 & 0 & 4 & 0 & 4 & 97 \\
\hline Total & 26 & & 812 & 240 & 12 & 12 & 0 & 89 & 1165 \\
\hline
\end{tabular}

TABLE II: QUALITY CHARACTERISTICS - CASE STUDY I

\begin{tabular}{|c|c|c|c|c|}
\hline \multicolumn{2}{|c|}{ No Process } & \multicolumn{2}{|c|}{ With Process } & \multirow{2}{*}{ Quality Characteristics - Case Study I } \\
\hline Total & $\%$ & Total & $\%$ & \\
\hline 13 & 100 & 3 & 23 & Does the requirement specify a true need, desire or obligation? \\
\hline 5 & 38 & 13 & 100 & Have you identified the root cause that necessitates the requirement? \\
\hline 12 & 92 & 3 & 23 & Is the requirement complete? \\
\hline 13 & 100 & 13 & 100 & Is the requirement stated as a complete sentence? \\
\hline 13 & 100 & 12 & 92 & Is the requirement clear? \\
\hline 1 & 8 & 12 & 100 & Does everyone agree on the meaning of the requirement? \\
\hline 13 & 100 & 13 & 100 & Is the requirement consistent? \\
\hline 13 & 100 & 13 & 100 & Is the terminology used consistent with other requirement and glossary terms? \\
\hline 13 & 100 & 13 & 100 & Can you determine whether the system satisfies the requirement? \\
\hline 0 & 0 & 0 & 0 & Is the requirement uniquely identified so that it can be referenced unambiguously? \\
\hline 10 & 77 & 8 & 62 & Is it possible to determine whether the requirement has been met through inspection, analysis, demonstration, or test? \\
\hline 13 & 100 & 13 & 100 & Is it possible to modify the requirement? \\
\hline 5 & 38 & 13 & 100 & Is the requirement verifiable? \\
\hline 13 & 100 & 13 & 100 & Is the requirement feasible? \\
\hline 4 & 31 & 0 & 0 & Can the requirements be satisfied within budget and on schedule? \\
\hline 13 & 100 & 13 & 100 & Is the requirement physically achievable? \\
\hline 13 & 100 & 1 & 8 & Is the requirement atomic? \\
\hline 13 & 100 & 13 & 100 & Does the requirement statement define exactly one requirement? \\
\hline 5 & 38 & 3 & 23 & Is the requirement statement free of conjunctions (and, or, but) that could indicate multiple requirements? \\
\hline
\end{tabular}

The project teams used the Software Development Methodology proposed by [18]. The projects lasted for one (1) year, being six (6) months for to the phases: Hiring, Analysis and Project and the requirements elicitation had already been made using traditional methods: Interviews, Workshops, Brainstorming and Scenarios. After the conclusion of the 
Project phase the teams applied the proposed approach and the result is described in Table I where the projects are identified as cases.

It can be seen that there was an elevated percentage (about $25 \%$ ) of requirements elicitation late in the phase of analysis, project and construction and that after the preliminary application of the proposed approach the average of $7.59 \%$ more of requirements were discovered (Fig. 3).

The customer found the requirements raised in both elicitations (with and without the proposed approach) through a survey (Checklist of Verification adapted from [19]) at the end of each step to investigate the characteristics of quality regarding to the requirements. A discrepancy in the obtained percentages can be spotted, as: The requirements specify a real need, desire or obligation. Without the process $100 \%$ of the customers agreed with the characteristic item and after the approach application only $23 \%$ of these agreed with what they had assessed before, as explained in Table II.

Furthermore, it was possible to see that the process modeling, even with orientation and constant presence of the analysts, demands a great effort on the part of analysts in the comprehension and abstraction of what business flow is and what system flow is.

TABLE III: REQUIREMENTS/PHASE OF THE PROJECT - CASE STUDY II

\begin{tabular}{|c|c|c|c|c|c|c|c|c|}
\hline Projects & Team & Technique Applied & Hiring & Analysis & Design & Build & Transition & Total Requirements \\
\hline Case I & 3 & Approach & 94 & 0 & 4 & 0 & 0 & 98 \\
\hline Case II & 1 & Approach & 49 & 0 & 1 & 0 & 0 & 50 \\
\hline Case III & 4 & Approach & 87 & 1 & 0 & 0 & 0 & 88 \\
\hline Case VI & 2 & Approach & 44 & 0 & 1 & 0 & 0 & 45 \\
\hline Case VI & 2 & Approach & 85 & 4 & 3 & 5 & 0 & 97 \\
\hline Case VII & 4 & Approach & 46 & 0 & 2 & 1 & 0 & 49 \\
\hline Case VIII & 2 & Approach & 94 & 0 & 4 & 0 & 0 & 98 \\
\hline Case IX & 3 & Approach & 42 & 5 & 4 & 0 & 0 & 51 \\
\hline Total & 24 & & 636 & 13 & 21 & 8 & 0 & 678 \\
\hline
\end{tabular}

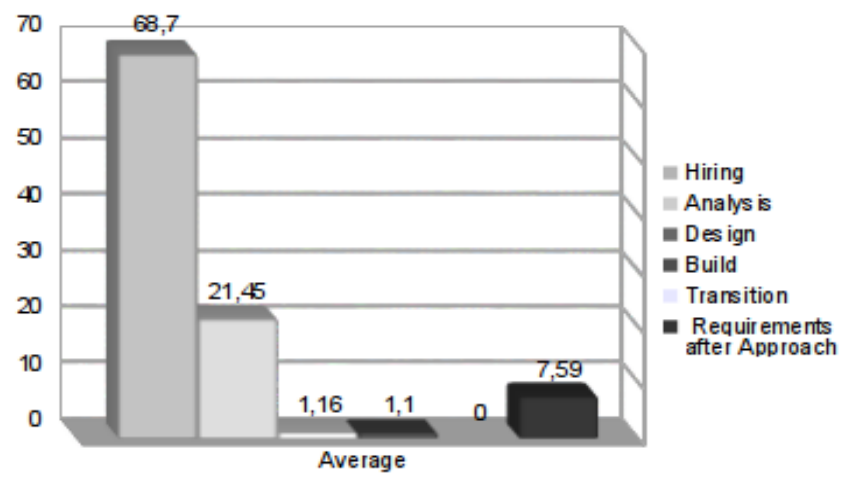

Fig. 3. Average requirements per phase of the project.

\section{B. Stage II}

Use of the approach, with the objective of applying it. Held in 9 projects all of them using the Software Development Methodology proposed by [18], such as: Automation of acquisition process, Inventory Management, Academies and Beauty Salons automation among others. The projects lasted one (1) year being six (6) months for the phases: Hiring, Analysis and Design. The proposed approach was applied soon at the beginning of the projects, more precisely in the Hiring Phase; the obtained results can be seen in Table III for the comparison.

It was also applied by customers, with the purpose of verification of requirements, a survey (Checklist of Verification adapted from [19]) at the end of each project stage to investigate the characteristics of quality regarding to the requirements.

As a result it is possible to see that more than $80 \%$ of the requirements elicitation was made in the Hiring Phase, representing an average of $94 \%$ of the total (Fig. 4) and not in a late form, as observed in the research first stage.

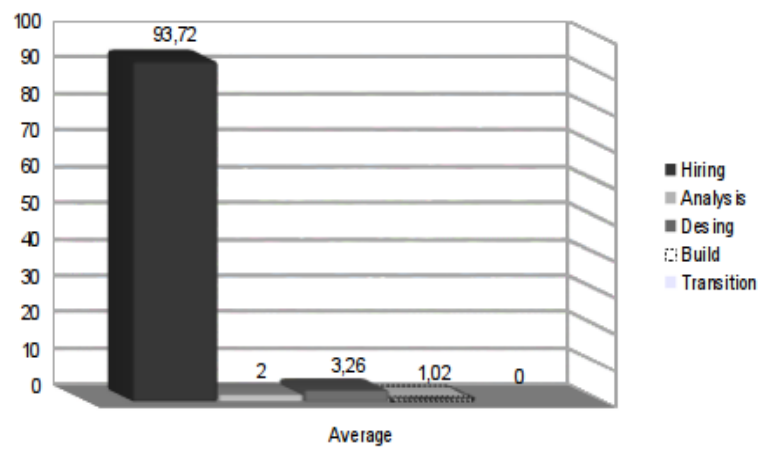

Fig. 4. Average requirements per stage.

The difficulties reported in the first stage (abstracting process and needs of business of solution development) were repeated. It is worth noting also, that the requirement identification, functional or not, for traceability purposes, proved fragile, forcing the creation of attributes in the requirement description document. This became necessary once the solution for process mapping, the tool Bonita Studio, did not present a space intended for this.

\section{Stage III}

Validation of the approach, with the objective of evaluating the effectiveness of the proposal will be performed along the software development companies with certification MPS-BR Software, and as a result, it is expected to have a notion of how the application of the modeling of business processes is used with the objective of assisting in 
elicitation of requirements. According [20] to validate the feasibility of the use of the approach proposed, it is necessary the implementation of an exploratory survey, in which were chosen approximately 83 companies all with certification MPS-BR level A to F [21].

With the implementation of the method, the quantity of listed requirements in both first and second stages (Fig. 5) was evidenced. Revealing an increase seen in the first stage, regarding the discovered requirements in the analysis, project and construction phases, in relation to the second stage where the vast majority of requirements, approximately $94 \%$, were found in the recruiting phase.

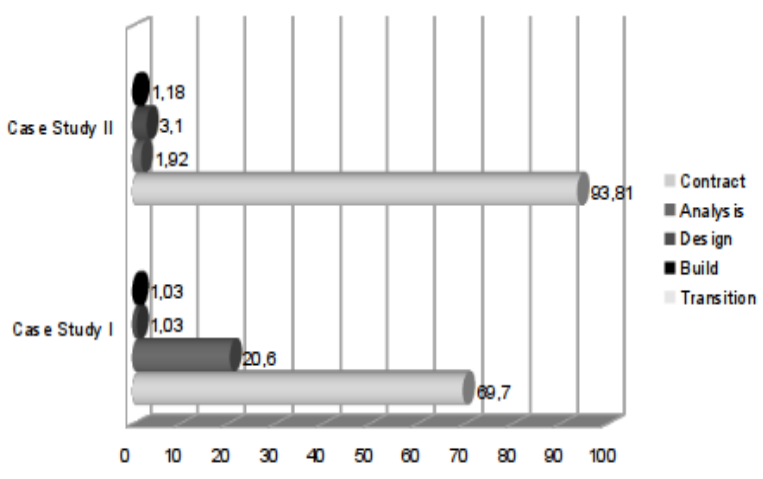

Fig. 5. Requirements difference for case study.

\section{RELATED WORK}

In literature, different proposals for requirements elicitation, based on the business process modeling, mapped with the notation BPMN, were identified.

Ref. [22] understand that the notation BPMN needs to be extended to improve the ability to represent the "operational behavior and the associate processes restrictions". Still, they argue, that the representation of these characteristics soon in the early stages, will allow the developers team to determine all of the details of the non-functional requirements. In their work two extensions are proposed: "Operating Status" for the representation of restrictions of business processes and "Case-control" for the description of risks.

Ref. [7] in his approach denominated Use Process, uses elements of notation BPMN together with the UML diagram of Use Cases. In his research, he reports that it was possible for the customers to identify and correct problems in their process, making it easier for the requirements elicitation in accordance with the business needs.

Ref. [8] defend that the notation BPMN is more appropriated as input for the development team, but at the same time, it is more complex. For [23] the identification of non-functional requirements is ad-hoc, late and not adherent to the needs of the organization business, his research proposes a systematic form of identification through procedures, instructions and tools.

Ref. [6] presents a mechanism of non-functional requirements through the elements of the BPMN, allowing the insertion of these requirements operational features in the business processes diagrams. In his approach, denominated BPMNFR, he proposes the creation of an extension to the notation BPMN for the elicitation of non-functional requirements.
Corroborating with [22], [24] argue that the non-functional requirements can be extracted from the functional requirements of the business, by proposing the creation of extensions in models based on notation BPMN, for extraction of quality requirements.

Thus, the authors use the business process modeling, with the use of notation BPMN, to facilitate the understanding and the elicitation of requirements.

Different from the other approaches researched that lead to the generation of certain requirements that support a small set of activities in the business process, the proposed approach presented in this article, allows the generation of several requirements and those in compliance with: Business strategies, development process, organizational alignment, legal and technological restrictions and internal and external policies.

\section{CONCLUSION}

This article presents a proposal of an approach to the requirements elicitation based on notation BPMN, with this it is intended to assist the requirements analysts in the task of software requirements elicitation. The approach evaluation was divided in three stages, two of them already completed.

With the implementation of the first two stages of the research, in which undergraduate students applied the proposed approach, it can be observed that the process modeling requires considerable effort in the understanding and abstraction of what the business flow is and what the system flow is. It was also observed that the requirements identification for traceability purposes seemed fragile, forcing the creation of another attribute in the requirements document for this end.

Based on preliminary results, it can be said that the use of the proposed approach allows the requirements analyst, together with the projects manager and the customer, to view the roll of the information system in detriment of the business strategic needs, facilitating the requirements identification and prioritizing them, in addition to allowing the mitigation of problems related to the scope, understanding and volatility of the requirements to be automatized.

However, it is important to highlight the need to generate more studies related to the use of notation BPMN for support to the requirements elicitation practices. It is important to emphasize that this work has proposed, initially, to establish an approach integrated with the concepts, methods and BPMN's Tools to the requirements elicitation process.

Therefore, in the future work will be performed with the objective of evaluating the effectiveness of the proposal. This evaluation will be held in partnership with software development companies with certification MPS-BR Brazilian Software Process Improvement [21].

Other applications of this approach in different processes and organizational contexts become necessary for its consolidation and proving of its benefits.

\section{REFERENCES}

[1] M. J. Brito, L. M. Antonialli, and A. C. Santos, "Tecnologia da informação e processo produtivo de gestão em uma cooperativa um enfoque estratégico," Revista de Administração Contemporânea, scielo, vol. 1, pp. 77-95, 1997. 
[2] P. Kruchten, Introdução ao RUP Rational Unified Process, 2st ed., Rio de Janeiro, RJ: Ciência Moderna, 2003.

[3] D. Lefilngwell and D. Widrig, Managing Software Requirements: A Use Case Approach, 2st ed., [S.1.]: Addison-Wesley Professional, 2003 Hardcover.

[4] I. Jacobson, G. Booch, and J. Rumbaugh, The Unified Software Development Process, 2st ed., Massachusetts: Addison Wesley Longman, Inc, 1999.

[5] E. A. Carvalho, T. Escovedo, and R. N. Melo, "Using business processes in system requirements definition," Software Engineering Workshop (SEW), 33rd Annual IEEE, 2009. pp. 125-130.

[6] L. Xavier, "Integração de Requisitos Não-Funcionais a Processos de Negócio: Integrando BPMN e RNF,” M.S. thesys, Computing Center, Federal Univ. of Pernambuco, Pernambuco, Brasil, 2009.

[7] U. I. Hernandez, F. J. A. Rodriguez, and M. V. Martin, "Use processes - modeling requirements based on elements of bpmn and uml use case diagrams," International Conference on Software Technology and Engineering, 2010, vol. 2, pp. V2-36-V2-40.

[8] C. Monsalve, A. April, and A. Abran, "Requirements elicitation using BPM notations: focusing on the strategic level representation," in Proc. the 10th WSEAS International Conference on Applied Computer and Applied Computational Science, Stevens Point, Wisconsin, USA: World Scientific and Engineering Academy and Society (WSEAS), 2011, pp. 235-241.

[9] OMG. (Mach 2013). Business Process Model and Notation (BPMN). [Online]. Available: http://www.omg.org/spec/BPMN/2.0/.

[10] G. S. Reis, Modelagem de processos de negócio com BPMN, 1st ed., São Paulo, SP: Editora PortalBPM Ltda, 2008.

[11] I. Sommerville, Engenharia de Software, 8st. ed., São Paulo, SP Pearson Addison Wesley, 2007.

[12] IEEE Std 610.12-1990. (September 1990). Standard Glossary of Software Engineering Terminology, IEEE Standards Board, New York, USA.

[13] M. A. Chiarello. (January 2013). Guia de utilização da notação BPMN [Online]. Available: http://www.frameworkpinhao.pr.gov.br/.

[14] T. Cruz, Business Process Management and Business Process Management Systems, 1st ed., Tijuca, RJ: Brasport, 2008, pp. 199-204

[15] IBM. (June 2013). Modelagem, Análise e Desenho de Processos de Negócio com BPMN. [Online]. Available: https://www.ibm.com/developerworks/mydeveloperworks/wikis/home /wiki/IBMBPMinAction/page/BPMSandbox.com?lang=en/.

[16] M. Bitencourt. (August 2012). Modelagem, Análise e Desenho de Processos de Negócio com BPMN. [Online]. Available: https://www.ibm.com/developerworks/mydeveloperworks/wikis/home /wiki/IBMBPMinAction/page/BPMSandbox.com?lang=en/.

[17] Bonita Soft. (January 2013). Understanding Process Automation: Tools for BPM. [Online]. Available: http://br.bonitasoft.com/resources/documentation-library-pt-br.

[18] M. A. Chiarello and D. T. Mayer. (May 2013). Framework Pinhão. [Online]. Available: http://www.frameworkpinhao.pr.gov.pr.
[19] IEEE Std 830.04-2004, Recommended Practice for Software Requirements Specifications: Standard Internacional, IEEE Standards Board, New York, USA, September 2004.

[20] A. Pinsonneault and K. L. Kraemer, "Survey research methodology in management information systems: an assessment," ACM J. of Manage Inf. Syst., vol. 10, no. 2, pp. 75-105, September 1993

[21] MPSBR. (May 2013). Melhoria do Processo do Software Brasileiro, Associação para Promoção de Excelência do Software Brasileiro. [Online]. Available: http://www.softex.br/mpsbr/_guias/guias/MPS.BR_Guia_ Geral_Software_2012.pdf.

[22] C. J. Pavlovski and J. Zou, "Non-functional requirements in business process modeling," in Proc. the fifth Asia-Pacific Conference on Conceptual Modelling, Darlinghurst, Australia, Australia: Australian Computer Society, Inc., vol. 79, 2008, pp. 103-112.

[23] R. V. Bitencourt, "Identificação de requisitos não funcionais de sistemas através de modelos de negócio," BDBCOMP Brazilian Digital Library of Computing, vol. 1, November 2008.

[24] K. Saeedi, L. Zhao, and P. R. Sampaio, "Extending bpmn for supporting customer facing service quality requirements," 2010 IEEE International Conference on Web Services (ICWS), Miami, Florida, 2010, pp. 616-623.

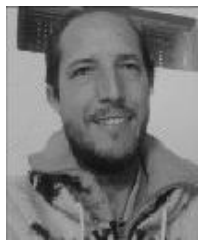

Marcos Chiarello received the BS degree in computing from Católica University of Paraná, Brasil. He is a researcher with the Federal Technological University of Paraná, Brasil. His research interests include software engineering, BPM, and requirements engineering.

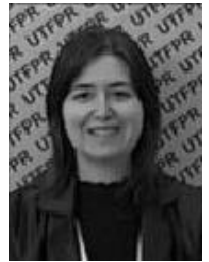

Maria Cláudia F. P. Emer holds a Ph.D. in electrical engineering from the State University of Campinas, Masters in Computer Science from the Federal University of Paraná degrees in Computer Science from the State University of West Paraná degree in Mathematics from the State University of West Paraná. She is currently an associate professor at the Federal Technological University of Paraná Department of Academic Computing (DAINF). Her area of interest is Software Engineering, working mainly in software testing.

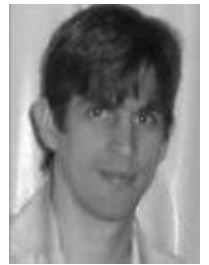

Adolfo Gustavo S. S. Neto has a PhD in computer science from the University of São Paulo (USP), Master in Computer Science from the Federal University of Pernambuco (UFPE) and a BS in Computer Science from the Federal University of Alagoas (UFAL). He is currently an associate professor at the Federal Technological University of Paraná Department of Academic Computing (DAINF) 